\title{
International Students Expectations from Online Education in Chinese Universities: Student-Centered Approach
}

\author{
Xinchao $\mathrm{Li}^{1} \&$ Isaac Kwaku Asante ${ }^{2}$ \\ ${ }^{1}$ Teaching Affairs Office-Jiangsu University, Jingkou District, Zhenjiang, Jiangsu, China \\ ${ }^{2}$ School of Teacher Education-Jiangsu University, Jingkou District, Zhenjiang, Jiangsu, China \\ Correspondence: Isaac Kwaku Asante, School of Teacher Education-Jiangsu University, Jiangsu, China. \\ Email: asanteisaac55@gmail.com
}

Doi: 10.23918/ijsses.v8i1p113

\begin{abstract}
The present study examined the relationships among variables of student-centered learning and online international students' satisfaction in two distinct universities in China (Jiangsu University and Jiangsu University of Science and Technology) after the advent of COVID-19 pandemic. The total participants for this study were two hundred and fifty (250) international students from the two Chinese universities. The studentcentered learning hypothesis were verified through structural equation modeling. The results showed that all the four constructs for student-centered learning- course flexibility, mode of collaboration, environment, and curriculum design, predicted online international students' satisfaction with proximity and program satisfaction are at a statistically significant level. The results provided an empirical student-centered understanding of online international student expectations. Further, it identifies that the universities' knowledge of online international students' expectation may help in designing an online educational campaign to tap into possible desires and decision-making around students in choosing online courses and to prepare students for a progressive online learning experience.
\end{abstract}

Keywords: COVID-19, International Students, Satisfactions, Student-Centered Approach

\section{Introduction}

With the advent of COVID-19 the whole world faced dramatic changes in the educational system. The biggest beneficiary of this unfortunate situation were international students in and out of their host country. Currently, most countries have not fully opened their schools for the traditional face to face instructions. Likewise, faculties are always of fear that students might infect them with the virus. To worsen the situation was hype that the COVID-19 is deadly disease intensified the fear both faculty and students have about the virus. In the quest for strategies to curb the effect this pandemic on educational institutions, governments and various universities employed strategies which will ensure secure faculty-student interaction. From this, Bettinger et al., (2020) reported that any strategy that mediates computer assistive learning with traditional learning will yield the same results at all educational levels. Fortunately, the pandemic forced governments around the globe to review their remote learning programs.

Received: January 13, 2021

Accepted: March 1, 2021

Li, X., \& Asante, I.K. (2021). International Students Expectations from Online Education in Chinese Universities:

Student-Centered Approach. International Journal of Social Sciences \& Educational Studies, 8(1), 113-123. 
Since online teaching and learning mode were not new to both teachers and international students in China, lesson plans were prepared far in advance for delivery of all online classes. Gewin (2020) believes COVID-19 pandemic only reinforces online mode of instruction in the universities, because many a faculty have had training in the use of online teaching platforms. But most universities roll out this remote learning as emergency responds teaching overlooking the fact that not all faculty are abreast with new technologies. With this, they employed various media in their delivery - e.g., the internet radio, mobile applications, text messages and TV. Thus, that form the basis for the universities to upgrade the technical departments, making online learning an integral part of the school system.

This intensive online mode of learning came as a relief to those international students who went home for the winter vacation before the lockdown. Though, most felt they might not get books, quality internet connection and computers to assist them in the online learning, faculty felt the time was right and their students are young and energetic to cope with the new technologies. Further, university authorities in China resorted to the social media apps and other e-learning platforms to promote constant flow of information to and from faculty and students. In this regard, faculty ensuring international students receiving information in electronic format promoted continuous academic study (Lau, 2020).

Before this pandemic, faculty-student interactions were mostly face to face. However, with the progress of internet technologies at global level, faculty-student relations have improved immensely because the role of internet technologies as input, output, and social environment are indispensable and highly recognized (Sykes, 2017). It befalls on university authorities and faculty to exploit to greater extent the merits of internet for advancement of knowledge (Furstenberg, Levet, English, \& Maillet, 2001; Sykes, 2017; Luo \& Yang, 2018). As China is advanced in internet connectivity, educators in Chinese universities must embrace current internet-mediated skills which are relevant for students' intellectual advancement. Meanwhile, the significance of incorporating online learning into international education is well understood, however few studies have been empirically reported on online learning in the contest of student-centered program development and design (Li, 2014).

Online learning has increased its share in modern higher education due to continuous interest by international students to study online (Shah \& Jarzabkowski, 2013). To sustain international students interest, faculty must focus on students' expectations to design and deliver online education that satisfies the student, facilitate robust outcomes that validate institutional, public and international student investment (Shah \& Jarzabkowski, 2013). International student expectations of online learning, however, stay under-study (Wieser \& Seeler, 2018). Formerly, online learning studies focus on the within institution expectations and defined constructs neglecting understanding of online student expectations in the holistic manner (Social Research Centre, 2019).

Current findings have proposed that higher educational institutions must build a framework which ensures an all-inclusive understanding of who and what their online students might need (Balloo, 2018; Stone \& O'Shea, 2019). In addition, understanding students' expectations and requirements allows academic institutions to design program to meet these needs and encourage learners to make strong outcomes. If their encounters are shown to have met their goals, students are more likely to feel fulfilled and continue with their studies (Ghazal, Al-Samarraie, \& Aldowah, 2018). 
In conventional higher education, the value of the overall student experience is well documented (Crane et al., 2016) . Conversely, awareness of online student expectation is based on academic experience (Paulsen \& McCormick, 2020). Further, few studies have explored online student expectation in the student context, such as course flexibility, mode of collaboration, environment, and curriculum design. Again, assumptions of aspirations of students are frequently inferred from the conventional Higher Education perspective (Weldy, 2018).

This study draws on the principles of Constructivist Learning Theory (Ashton-Hay, 2006), which postulates that deep learning needs active, student-centered curriculum design, cognizant with prior knowledge, and subjective to the student's sociocultural experiences ( Wlodkowski \& Ginsberg, 2017; Lesgold, 2004). In this regard, the current study seeks to answer the research question; will the relative significance of the student-centered variables influence students' expectations in an online learning environment? Together, we hypothesis that a higher student-centered variables have positive association with online international students' satisfaction.

\section{Methods}

We tested the hypotheses for this study using self-design quantitative surveys of online international students' expectation based on student-centeredness and satisfaction. Those international students who participated in this survey were enrolled in online courses at Jiangsu university and Jiangsu University of Science and Technology in China. Structural equation modeling was used to test the possible effect of the student- centered variables on online international students' satisfaction.

\subsection{Study Participants}

The participants who took part in this study were those who went home during the 2019 winter vacation. The total participants were two hundred and fifty (250) international students. Out of 250 participants, one hundred and fifty (150) were males and hundred (100) were females. They were enrolled in 5 to 8 online courses within their major program in two Chinese universities in China. The participants comprised of students from undergraduate to doctoral-level classes within disciplines of education, liberal arts, and sciences. The diversity among international students in both universities were in terms of age, ethnic status, and academic background. Participant were ranged between 21 and 50 with a mean value 35 . International students from Asia form 53 percent of the participants, followed by Africans 20 percent. Each of the instructors who taught the online courses had more than 3years online instruction experience.

\subsection{Measures}

To achieve the purpose of this study, we employed the following measures for the online-learning environment, within the premises of the above-mentioned constructs of student-centered learning. The survey contains 27 items in six scales. The first four constructs are course flexibility, mode of collaboration environment and curriculum design and online international students' satisfaction. The alpha reliability coefficient of the six scales of the survey ranged from .70 to .93 (Walker \& Fraser, 2005). 


\subsection{Data Collection and Analysis}

The self-design questionnaires were sent to participants through Chinese social media Wechat. The data collection started from October 2020 and ended on 31 November 2020. All participants who received the questionnaire acknowledged received and responded accurately to almost all the survey questions. After all data have been received, the researchers examined the data for missing values. Out of the 300 participant who acknowledged receipt of the survey, 50 of them data were incomplete which were removed. A structural equation modeling (SEM) approach was used with the survey results to assess the data and to gain accurate understanding on the potential relationships between international students' expectation on online learning and their level of satisfaction toward online courses.

\subsection{Proposed Model}

Figure 1 shows the proposed structural equation model that guided the design and data analysis of this study. This model was design in association with the literature in this study. The model used two-phase SEM approach to verify the reliability and validity of the data ( Hair Jr, Matthews, Matthews, \& Sarstedt, 2017; Anderson \& Gerbing, 1988). The model was first examined using confirmatory factor analysis (CFA) for the overall goodness-of-fit reliability and validity. Second, the structural equation modeling was employed to validate the hypothesis between the constructs.

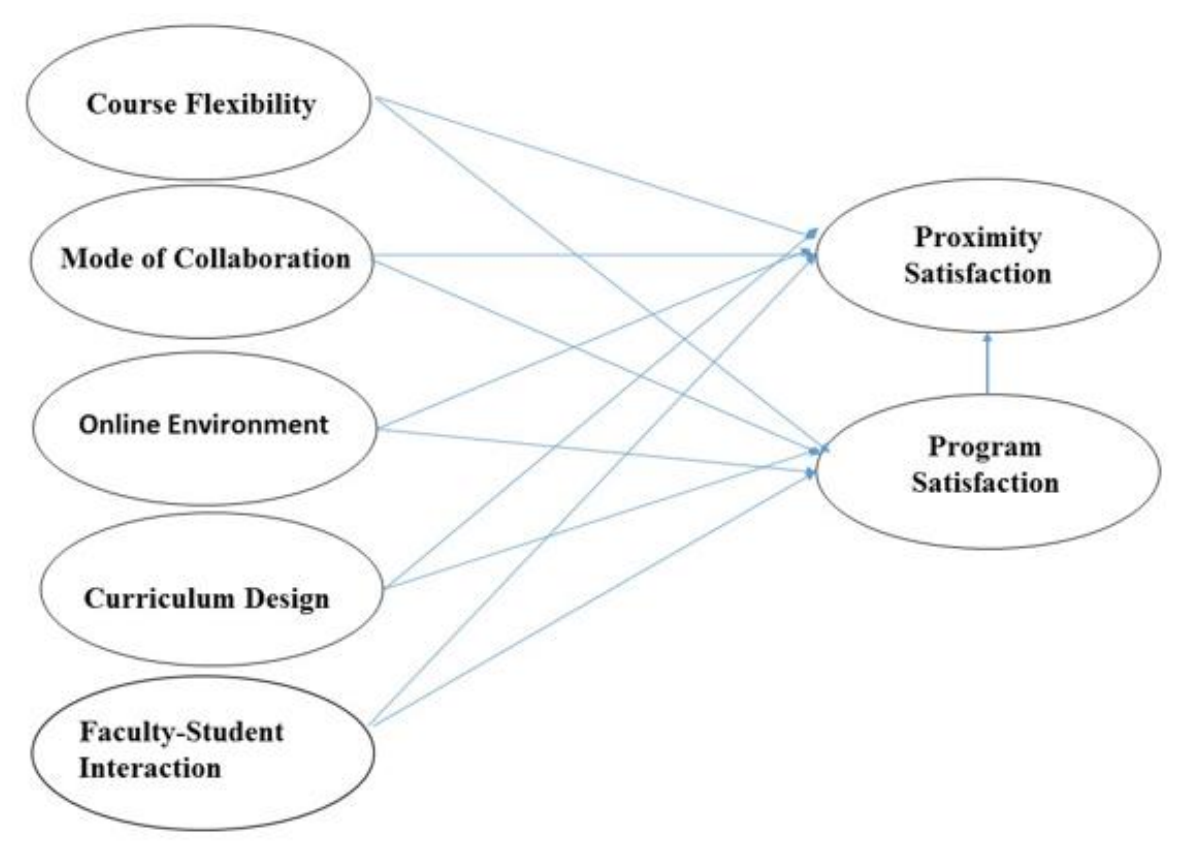

Figure 1: Proposed model for this study

\section{Results}

\subsection{Model Fit Indices}

The test for model fit in this study employed fit indices (Hu \& Bentler 1999) have suggested. The following fit indices were used to verify the models' goodness-to-fit: the chi-square per degree of freedom ratio 
(X2/df), root mean square error of approximation (RMSEA), goodness of fit index (GFI), Tucker-Lewis index (TLI), and comparative fit index (CFI). These indicators have their criteria and values verification shown in Table 1.

Table 1: Goodness of fit indices for the model

\begin{tabular}{|l|l|l|}
\hline Fit Index & Criteria & Results \\
\hline $\mathrm{X}^{2} / \mathrm{df}$ & $<3$ & 1.266 \\
\hline CFI & $>0.9$ & 0.95 \\
\hline GFI & $>0.9$ & 0.98 \\
\hline TLI & $>0.9$ & 0.96 \\
\hline RMSEA & $<0.05$ & 0.02 \\
\hline
\end{tabular}

The initial fit indicators proved unsatisfactory to the model. A model modification was initiated among the constructs. This modification helped to improve the fit index for the model. Thus, there was no statistically significant of the effects of faculty-student interaction on online-learning students' satisfaction. The variable faculty-student interaction was removed from the initial model (see Figure 2). This modification to the initial model significantly enhanced the model fit index. Table 1 indicate the summary of the model fit indices. Therefore, we conclude that the modified model demonstrated a good fit to the data.

Table 2: Correlation matrix for the measurement variables of the model

\begin{tabular}{|c|c|c|c|c|c|c|}
\hline & 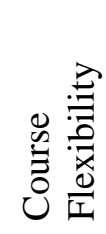 & 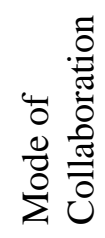 & 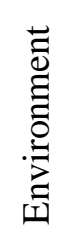 & 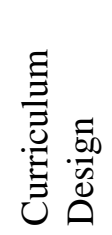 & 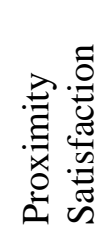 & 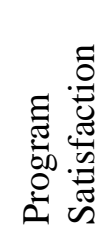 \\
\hline Course Flexibility & .32 & & & & & \\
\hline Mode of collaboration & .40 & .32 & & & & \\
\hline Environment & .13 & .44 & .65 & & & \\
\hline Curriculum Design & .39 & .35 & .37 & .53 & & \\
\hline Proximity Satisfaction & .35 & .39 & .23 & .09 & .28 & \\
\hline Program Satisfaction & .43 & .32 & .48 & .39 & .20 & .65 \\
\hline
\end{tabular}




\subsection{The Test for the Model's Reliability and Validity}

The structural equation model was used to justify the reliability and validity of the model constructs. The evaluation of factor loadings, reliability, and convergent validity were performed on the latent constructs through a confirmatory factor analysis (CFA)( Hair, Black, Babin, Anderson, \& Tatham, 2006; Bagozzi $\& \mathrm{Yi}, 1988$ ). The model factor loadings are indicated in Table 2 . For convergent validity to be statistically significant; factor loadings of the indicators must be not less than 0.707 ; composite reliability (CR) with values greater than 0.6; and average variance extracted (AVE) with values greater than 0.5 ( Hair Jr et al., 2017; Bagozzi \& Yi, 1988).

Table 3: Composite and Average validity for the measured constructs

\begin{tabular}{|l|l|l|l|}
\hline Constructs & $\begin{array}{l}\text { Indicators } \\
\text { a (Survey Items) }\end{array}$ & $\begin{array}{l}\text { Composite } \\
\text { Reliability }\end{array}$ & AVE \\
\hline Course Flexibility & 5 & .89 & .67 \\
\hline Mode of collaboration & 5 & .87 & .69 \\
\hline Environment & 4 & .82 & .71 \\
\hline Curriculum Design & 5 & .93 & .67 \\
\hline Proximity Satisfaction & 4 & .86 & .65 \\
\hline Program Satisfaction & 4 & .89 & .71 \\
\hline$a$ factor loading of the individual items are statistically significant $(p<0.01)$. \\
\hline
\end{tabular}

Table 2 shows that all the factor loadings were statistically significant ranging from 0.71 to 0.93 which are above the criterion of 0.707 (Hair Jr et al., 2017). This indicated that individual item in the model related positively with its respective construct because all the variances among the indicators were explained by the latent constructs. Also, the composite reliability values were greater than 0.6 , indicating a reliable model. AVE values explained the variance through latent construct. The AVE relied on the ratio of the sum of each specific item variance as extracted by the measured construct in relation to the standard error attributed to each item. The AVE values between 0.65 and 0.71 , hence each construct was strongly related to its associated indicators. Together, the model for this study exhibited satisfactory convergent validity.

\subsection{Structural Equation Model for Hypothesis Testing of the Constructs}

The study used the modified structural equation model to evaluate fit indices in the model. Table 4 revealed all model fit indices were appropriate to the structural equation model. Accordingly, it was settled that the study's structural equation model had a good fit to the model see Figure 3. The estimates for the path coefficient (standardized) with its significance level are indicated to each link. Again, the R2 statistic is shown close to the endogenous constructs. The results revealed that the model explained 0.41 of the variances in proximity satisfaction and 0.43 of the variances in program satisfaction. The Table 4 is the summary of the standardized direct effects for the analysis. 


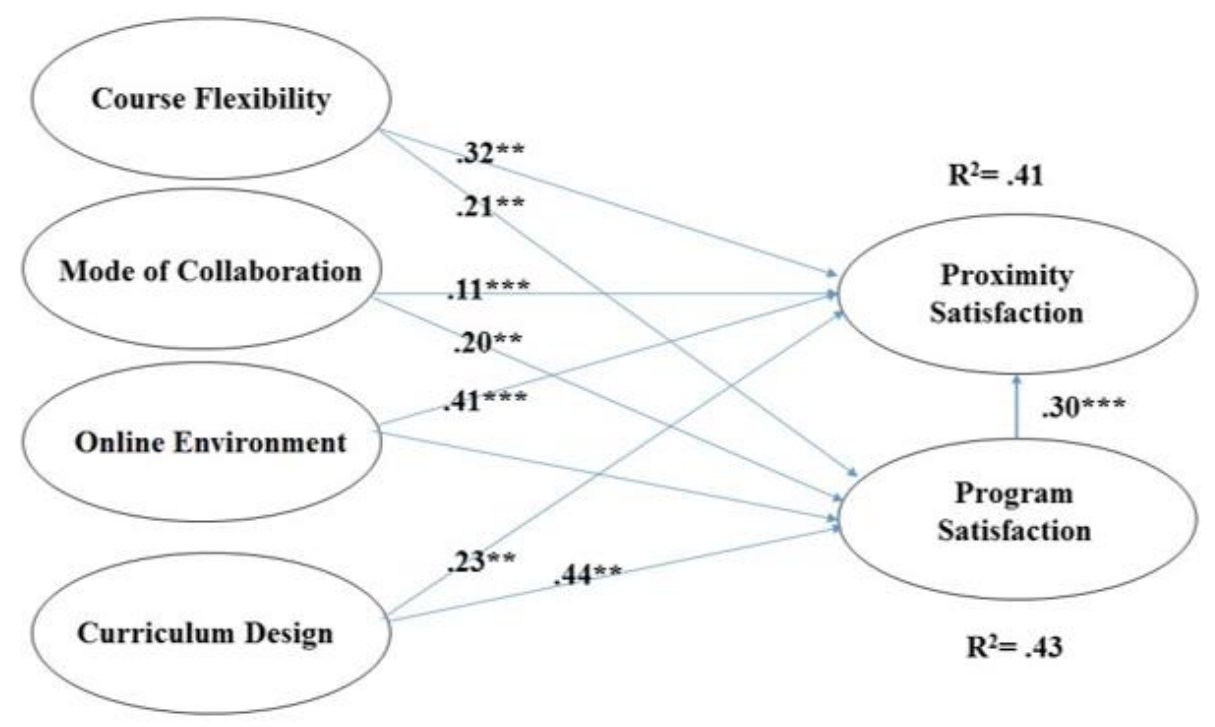

Figure 2: Hypothesis testing result

The testing of the hypothesis as seen in Table 4, indicated that the effect of student-centered learning variables on the online international students' satisfaction were generally supported. Individual constructs were used to explain the hypothesis; thus, the course flexibility positively influence the proximity satisfaction $(\beta=.32, p<0.01)$. In all, the constructs of course flexibility, mode of collaboration, online environment and curriculum design accounted for $41 \%$ of the variance of the online international students' satisfaction.

Table 4: Direct effects for the model

\begin{tabular}{|l|l|l|l|}
\hline & Proximity Satisfaction & \multicolumn{2}{l|}{ Program Satisfaction } \\
\hline & Direct Effects & Direct Effects & $\begin{array}{l}\text { Indirect } \\
\text { effect }\end{array}$ \\
\hline Course Flexibility & .32 & .21 & .02 \\
\hline Mode of collaboration & .11 & .20 & - \\
\hline Online Environment & .41 & - & .08 \\
\hline Curriculum Design & .23 & .44 & .04 \\
\hline Total $\mathrm{R}^{2}$ & .41 & .43 & \\
\hline
\end{tabular}

Again, the direct effect of student-centered learning variables on program satisfaction were positively significant, showing that the student-centered variables of course flexibility, mode of collaboration and curriculum design had direct positive effects $(\beta=.21,41$ and .44$)$ on the total program satisfaction construct. Online environment was not supported as it had no direct association with the overall program satisfaction. Even though online environment had no significant direct effect on the overall program satisfaction. Yet, it had a significant indirect effect on the dependent variable $(\beta=.08)$. The results also revealed that program satisfaction had a direct positive effect on proximity satisfaction. 
While course flexibility, mode of collaboration, and curriculum design had direct positive significant effects on the program satisfaction, course flexibility, online environment and curriculum design all had indirect impact on this endogenous variable. In all, student-centered variables had a direct and indirect effects on the overall international students' satisfaction explaining $43 \%$ of its variance.

\section{Discussion}

Student-centered learning form integral part of modern instructional design models for online education. This study used a theoretical model to examines the main the student-centered constructs and their effects on the online international students' satisfaction. The results provided a significant effect on online international students' satisfaction, as presented in Figure 2. The estimate 0.41 for the online international students' satisfaction constructs $(\mathrm{R} 2=41 \%)$ support the hypothesis and its influence on student-centered learning on students' proximity satisfaction. Further, the estimate 0.43 for the program satisfaction construct $(\mathrm{R} 2=43 \%)$ suggested a support of the hypothesized effect on student-centered learning constructs on students' overall program satisfaction with online education.

The study results basically resonates with the constructivists propositions on the positive effect of studentcentered learning approach in online education (Teo, Zhou, Fan, \& Huang, 2019; Hannafin \& Kim, 2003). Also, the findings in this study indicate that the model has strong descriptive influence on how studentscentered learning predicts online international students' satisfaction.

The results suggest online international students in Chinese Universities know the role they play in their online study experience. In this regard, Hassel \& Ridout (2018) posit that faculty should be mindful of the way online courses are design to suit their students' interest. As students are already aware of their capability and wiliness to succeed. For instance, Swan (2003) believes that online education should individualize instruction such that they provide each student with study plans, student-centered content and evaluation, individual feedback aside collective feedback, and presenting individualized flexibility both time and study experiences. With this, students expect faculty to assist in their technical skills and academic endeavors, content familiarity, self-regulation and persistent to concentrate (Hassel \& Ridout, 2018). Online international students might not be aware of the required level of time commitments, and their ability to cope with their schoolwork whiles dealing with family duties or health issues (Stone \& O'Shea, 2019; Su \& Waugh, 2018). Online instructors might design a content which is flexible to students to assist in managing their studies and to be proactive.

Beside students' individual depositions, they hold strong expectations of their university, about curriculum, online learning environment and mode of collaboration. That is to say, online international students expect reliable interaction, support, and feedback from online instructors, quality course content, and a means to connect with peers for academic and social support from the universities (Stone \& O'Shea, 2019). They expect their instructors' curriculum to be flexible, stimulating and applicable (Stone, 2017); and encourage potential challenges. Online international students do not anticipate to be passive students (Hayes, Smith, \& Shea, 2015). Again, the study identify that online international students require a quality online learning environment, liking to presumed on-campus experience (Stone \& O'Shea, 2019). Therefore, these expectations go beyond academics and reveal potential difficulties and personal responsibilities, in addition to earlier understanding. 
The study found an opportunity to improve online student expectation through identification of what students might seek from online education. The university's knowledge of online international students' expectation may be helpful in designing online education campaign to tap into possible desires and decision-making around students choosing online course to prepare students for a progressive online learning experience. Universities considering students' expectations, goals and evaluating previous knowledge and experiences may assist in placing students on most suitable study pathways. Likewise, prospective online international students may benefit from concise information about expected student schedules, level of flexibility, time commitments, technical requirements, levels of interaction and essential skillsets. This information may help online international students to make informed decisions and successfully prepare for their studies.

The study suggests that universities in China should juxtapose their online education policies, standards and quality assurance mechanisms with online faculty-student interaction, curriculum design, and online learning environment to ensure its direct correspondent with students' expectations. Again, universities should understand the position of online international students to design appropriate support which is flexible and accessible to help students contribute and succeed in their online education (Stone, 2017).

\section{Conclusion}

This study empirically examined online international students' expectation through student-centered approach. The study contributed to online international students in Chinese universities needs in this era of COVID-19 pandemic. The results add to an understanding of the total online international student experience and apprise universities of how best they might adjust to the rising expectations of online international students. An in-depth knowledge about what online students require of Chinese universities will assist the institutions to improve student satisfaction and retention as well as enhancing their global competitiveness. A future research might examine the connections between the online learning environment and international students' academic and psychological satisfaction using an alternative learning approach through longitudinal study.

\section{References}

Anderson, J. C., \& Gerbing, D. W. (1988). Structural equation modeling in practice: A review and recommended two-step approach. Psychological Bulletin, 103(3), 411.

Ashton-Hay, S. (2006). Constructivism and powerful learning environments: create your own!

Bagozzi, R. P., \& Yi, Y. (1988). On the evaluation of structural equation models. Journal of the Academy of Marketing Science, 16(1), 74-94.

Balloo, K. (2018). In-depth profiles of the expectations of undergraduate students commencing university: a Q methodological analysis. Studies in Higher Education, 43(12), 2251-2262.

Bettinger, E., Fairlie, R. W., Kapuza, A., Kardanova, E., Loyalka, P., \& Zakharov, A. (2020). Does edtech substitute for traditional learning? experimental estimates of the educational production function. National Bureau of Economic Research.

Crane, L., Kinash, S., Bannatyne, A., Judd, M.-M., Eckersley, W., Hamlin, G., ... Stark, A. (2016). Engaging postgraduate students and supporting higher education to enhance the 21st century student experience. Final Report 2016. Department of Education and Training.

Furstenberg, G., Levet, S., English, K., \& Maillet, K. (2001). Giving a virtual voice to the silent language of culture: The Cultura project. Language Learning \& Technology, 5(1), 55-102. 
Gewin, V. (2020). Five tips for moving teaching online as COVID-19 takes hold. Nature, 580(7802), 295-296.

Ghazal, S., Al-Samarraie, H., \& Aldowah, H. (2018). "I am still learning”: Modeling LMS critical success factors for promoting students' experience and satisfaction in a blended learning environment. IEEE Access, 6, 77179-77201.

Hair, J. F., Black, W. C., Babin, B. J., Anderson, R. E., \& Tatham, R. (2006). Multivariate data analysis . Uppersaddle River. NJ: Pearson Prentice Hall.

Hair Jr, J. F., Matthews, L. M., Matthews, R. L., \& Sarstedt, M. (2017). PLS-SEM or CB-SEM: updated guidelines on which method to use. International Journal of Multivariate Data Analysis, 1(2), $107-123$.

Hannafin, M. J., \& Kim, M. C. (2003). In search of a future: A critical analysis of research on web-based teaching and learning. Instructional Science, 31(4-5), 347-351.

Hassel, S., \& Ridout, N. (2018). An investigation of first-year students' and lecturers' expectations of university education. Frontiers in Psychology, 8, 2218.

Hayes, S., Smith, S. U., \& Shea, P. (2015). Expanding learning presence to account for the direction of regulative intent: self-, co-and shared regulation in online learning. Online Learning, 19(3), $15-31$.

Hu L.-T., \& Bentler P. M. (1999). Cutoff criteria for fit indexes in covariance structure analysis: conventional criteria versus new alternatives. Structural Equation Modeling , 6(July 2012), 155 .

Lesgold, A. (2004). Contextual requirements for constructivist learning. International Journal of Educational Research, 6(41), 495-502.

Li, L. (2014). Understanding language teachers' practice with educational technology: A case from China. System, 46, 105-119.

Luo, H., \& Yang, C. (2018). Twenty years of telecollaborative practice: implications for teaching Chinese as a foreign language. Computer Assisted Language Learning, 31(5-6), 546-571.

Paulsen, J., \& McCormick, A. C. (2020). Reassessing disparities in online learner student engagement in higher education. Educational Researcher, 49(1), 20-29.

Shah, M., \& Jarzabkowski, L. (2013). The Australian higher education quality assurance framework: From improvement-led to compliance-driven. Perspectives: Policy and Practice in Higher Education, 17(3), 96-106.

Social Research Center (2019). 2018 Student Experience Survey: national report

Stone, C. (2017). Opportunity through online learning: Improving student access, participation and success in higher education. Perth: The National Centre for Student Equity in Higher Education (NCSEHE), Curtin University.

Stone, C. M. M., \& O'Shea, S. E. (2019). My children... think it's cool that Mum is a uni student: Women with caring responsibilities studying online. Australasian Journal of Educational Technology, 35(6), 97-110.

Su, J., \& Waugh, M. L. (2018). Online student persistence or attrition: Observations related to expectations, preferences, and outcomes. Journal of Interactive Online Learning, 16(1), 6379.

Swan, K. (2003). Learning effectiveness online: What the research tells us. Elements of Quality Online Education, Practice and Direction, 4(1), 13-47.

Sykes, J. (2017). Technologies for teaching and learning intercultural competence and interlanguage pragmatics. The Handbook of Technology and Second Language Teaching and Learning, 119-133.

Teo, T., Zhou, M., Fan, A. C. W., \& Huang, F. (2019). Factors that influence university students' intention to use Moodle: A study in Macau. Educational Technology Research and Development, 67(3), 749-766. 
Walker, S. L., \& Fraser, B. J. (2005). Development and validation of an instrument for assessing distance education learning environments in higher education: The Distance Education Learning Environments Survey (DELES). Learning Environments Research, 8(3), 289-308.

Weldy, T. G. (2018). Traditional, blended, or online: Business student preferences and experience with different course formats. E-Journal of Business Education and Scholarship of Teaching, 12(2), $55-62$.

Wieser, D., \& Seeler, J.-M. (2018). Online, Not Distance Education: The Merits of Collaborative Learning in Online Education. In The Disruptive Power of Online Education. Emerald Publishing Limited.

Wlodkowski, R. J., \& Ginsberg, M. B. (2017). Enhancing adult motivation to learn: A comprehensive guide for teaching all adults. John Wiley \& Sons. 